\title{
Sound recognition in relation to aural language comprehension in aphasic patients
}

\author{
NILS R VARNEY \\ From the Psychology Service, Veterans Administration Medical Center and the Department of \\ Neurology, University Hospitals, Iowa City, Iowa, USA
}

S U M M A R Y This study was undertaken to determine whether some aphasic defects in aural language comprehension might be a reflection of cognitive impairment which also affects the recognition of meaningful, non-verbal sounds. Defects in sound recognition were consistently associated with aural comprehension defects of at least comparable severity and the majority of aphasics with impaired aural comprehension failed sound recognition. Although some aphasics with impaired aural comprehension performed normally in sound recognition, their language comprehension impairments were not of lesser severity than those shown by aphasics failing sound recognition. The relationship between sound recognition and reading comprehension was different in nature from that between sound recognition and aural comprehension.

That aphasic patients may show a variety of non-verbal impairments in addition to their linguistic symptoms has been well established. Hughlings Jackson ${ }^{1}$ was the first to note that these non-verbal impairments were shown primarily by aphasics for whom aural language comprehension was also significantly impaired. He deduced from this observation that comprehension defective aphasics suffered a general disturbance in both verbal and non-verbal understanding, with the result that they were "lame in thinking." At the same time, however, it has also been established that the non-verbal test performances of comprehension defective aphasics are quite variable, and that some may perform at average or better levels on tests of non-verbal abstract reasoning. ${ }^{2-4}$ Findings of this type have been emphasised by authors who regard aphasia as a specific disturbance of conventional language operations with determinants that are functionally distinct from those resulting in non-verbal defects. ${ }^{56}$

The results of studies on the recognition of meaningful sounds have particular relevance to this controversy. The basic task employed in these studies requires patients to identify familiar, nonlinguistic sounds-for example, dog bark, church bell, train whistle-by pointing to drawings depicting the source of each sound. Spinnler and

Address for reprint requests: Dr Nils $\mathbf{R}$ Verney, Psychology Service, VA Medical Center, Iowa City, Iowa, 52240, USA.

Accepted 14 June 1979
Vignolo $^{7}$ found defective performances of this test to be frequent among aphasics with impaired aural comprehension, but quite rare among other aphasics and patients with right brain damage. Similar findings were obtained in subsequent investigations by Faglioni $e t a l^{8}$ and Vignolo. ${ }^{9}$ In accord with Jackson's theories, the authors concluded that defects in sound recognition were the result of a basic cognitive distubance in which aural comprehension was also affected. However, the results reported in these studies also indicated that a significant minority of aphasics with impaired aural comprehension performed normally in sound recognition. While this aspect of the findings was not directly discussed, it appeared to be consistent with the idea that defects in aural comprehension could be specifically linguistic in nature.

Given the nature of these previous findings, it seemed possible that there might be two major types of aural comprehension defects in aphasia. In one type, similar to that hypothetised by Jackson, aural comprehension and sound recognition would be affected in conjunction by a single, shared determinant. In the other type, or types, aural comprehension would be affected by determinants which were more specifically linguistic in nature and which did not affect sound recognition. However, for this interpretation of previous findings to be corroborated, it was thought that three additional findings would have to be obtained. First, defects in sound recognition should be consistently associated with aural 
comprehension defects of at least comparable severity. This would indicate that defects in sound recognition are causally associated with defects in aural comprehension. Second, some aphasics with impaired aural comprehension should perform at significantly better intact levels in sound recognition. This would indicate that some aural comprehension defects involve determinants which do not affect sound recognition. Third, aphasics with impaired sound recognition should show aural comprehension scores similar in range to those of other comprehension defective aphasics for whom sound recognition is intact. This would indicate that impaired sound recognition is symptomatic of a distinct type of aural comprehension disorder rather than merely a reflection of severity of disorder.

\section{Methods}

Two groups of subjects, 40 aphasics and 20 controls, were selected from patient populations at the Veterans Administration Medical Center and University Hospitals in Iowa City, Iowa. All were righthanded, had at least an eighth grade education, were between 22 and 73 years of age, and had no history of psychiatric illness or hearing impairment. Inclusion in the aphasic group was restricted to patients with clinically apparent aphasic expressive symptoms who had lesions confined to the left hemisphere (as indicated by both neurological examination and neuroradiographic tests) and who demonstrated significant linguistic impairments in formal neuropsychological assessment (as indicated by performance below the fifth percentile on a standardised test of naming ability). The control subjects were hospital inpatients without past or present evidence of neurological disease. This group was used in the standardisation of the sound recognition test.

\section{TESTS}

Sound recognition The sound recognition test of Spreen and Benton ${ }^{10}$ was used to assess the ability to recognise familiar, non-linguistic environmental sounds-for example, dog bark, train whistle, running water. The 26 stimulus sounds were recorded on tape, and patients identified each sound by pointing to a drawing of its source from among four choices. The poorest control performance, obtained from one subject, was 22 correct responses. Performances below this level were classified as defective.

Aural comprehension This subtest from the
Multilingual Aphasia Examination ${ }^{112}$ requires patients to point to drawings of objects named by the examiner. Four response choices were available on each of the 21 test trials. Based on previous established norms, scores of dess than 18 correct (below the fifth percentile of controls) were classified as defective.

Reading comprehension This subtest from the Multilingual Aphasia Examination requires patients to point to drawings of objects whose name was shown in half inch type on a printed card. Four response choices were available on each of the 20 test trials. Based on previously established norms, scores of less than 18 correct (below the fifth percentile of controls) were classified as defective.

Conversion of test scores In order that performances on the above mentioned tests be expressed on comparable scales, raw scores were converted to standard scores, based on the number of standard deviations an individual raw score was above or below the criterion for defective test performance. Aphasic performances were used to compute the standard deviation, which for sound recognition was 4.9 points, for aural comprehension was 4.7 points, and for reading comprehension was 5.3 points. After this conversion, scores in sound recognition ranged from +0.9 to $-2.6 \mathrm{SD}$, scores in aural comprehension ranged from +0.7 to $-2.4 \mathrm{SD}$, and scores in reading comprehension ranged from +0.5 to $-2.4 \mathrm{SD}$, with a score of zero being at the criterion for defective performance.

\section{Results}

The performances of aphasics in sound recognition, aural comprehension, and reading comprehension were quite variable, ranging from errorless to grossly impaired on each test. Eighteen aphasics $(45 \%)$ failed sound recognition, $28(75 \%)$ failed aural comprehension, and $20(50 \%)$ failed reading comprehension. As can be seen from the table, defects in sound recognition were shown only by aphasics with defects in aural comprehension, and none of the aphasics for whom aural comprehension was intact failed sound recognition. However, there were 10 aphasics with impaired aural comprehension who performed normally in sound recognition. The reading comprehension scores of aphasics failing sound recognition were more variable, and four were found for whom reading comprehension was intact. 
Table 1 Contingencies of intact and defective test performance

\begin{tabular}{lcccc}
\hline \multirow{2}{*}{ Sound recognition } & \multicolumn{2}{c}{ Aural } & \multicolumn{2}{c}{ Reading } \\
& comprehension & comprehension \\
& Int & Def & Int & Def \\
\hline Int $(\mathrm{n}=22)$ & 12 & 10 & 16 & 6 \\
Def $(\mathrm{n}=18)$ & 0 & 18 & 4 & 14 \\
\hline
\end{tabular}

Int $=$ intact test performance

Def $=$ defective test performance

The implications of the contingency data were confirmed in a second analysis in which each aphasic's performance in sound recognition was compared with that in aural comprehension and reading comprehension. The distributions of differences between these tests, based on performance expressed as standard scores, are shown in the figure. For aphasics as a group, sound recognition was never more than $0.6 \mathrm{SD}$ poorer than aural comprehension, but there were 10 aphasics for whom aural comprehension was from 1.0 to $2.9 \mathrm{SD}$ poorer than sound recognition. In contrast, scores in sound recognition ranged from being 1.7 SD poorer to being 1.9 SD better than those in reading comprehension. In addition, there were three aphasics found for whom reading comprehension was $1.0 \mathrm{SD}$ or more better than sound recognition and aural comprehension, all with intact reading and defective sound recognition and aural comprehension. Thus, defects in sound recognition were consistently associated with aural comprehension defects of at least comparable severity, but some aphasics with impaired aural comprehension per- formed at significantly better, intact levels in sound recognition, and defects in sound recognition were not predictably associated with defects in reading comprehension..

Among aphasics failing sound recognition, scores in aural comprehension ranged from -0.1 to $-2 \cdot 4 \mathrm{SD}$, with the three best scores being $-0 \cdot 1,-0 \cdot 1$, and $-0 \cdot 3$ SD. Among the remaining comprehension defective aphasics, aural comprehension scores covered an identical range, and their three best scores were $-0 \cdot 1,-0 \cdot 3$, and $-0.5 \mathrm{SD}$. In reading comprehension, aphasics with impaired sound recognition showed even greater variability, with scores covering the full available range from +0.5 to $-2.4 \mathrm{SD}$. Thus, while all aphasics failing sound recognition were impaired in aural comprehension, their language comprehension test performances were otherwise quite variable. However, it should be noted that the seven poorest reading scores observed were all obtained from aphasics with impaired sound recognition.

The frequency of various characteristics among aphasics failing sound recognition in comparison with the frequency of that characteristic in the total aphasic sample was as follows : $12 / 26$ with vascular lesions, $6 / 12$ with neoplastic lesions, $0 / 2$ with head trauma; 5/10 fluent aphasics, 13/30 non-fluent aphasics; 7/12 females, $11 / 28$ males; $2 / 5$ with college degrees, $12 / 25$ with high school diplomas, $4 / 10$ with eighth to eleventh grade education; $3 / 9$ aged between 22 and 49 years, $10 / 22$ ages between 50 and 64 years, 5/9 aged between 65 and 73 years. None of these characteristics is differentially represented among aphasics failing sound recognition.

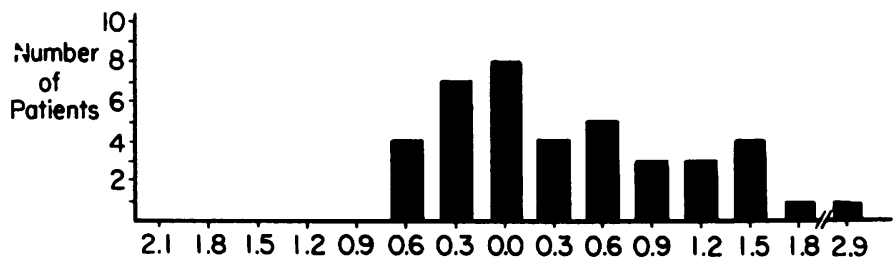

SR poorer thon AC

$A C$ poorer thon SR

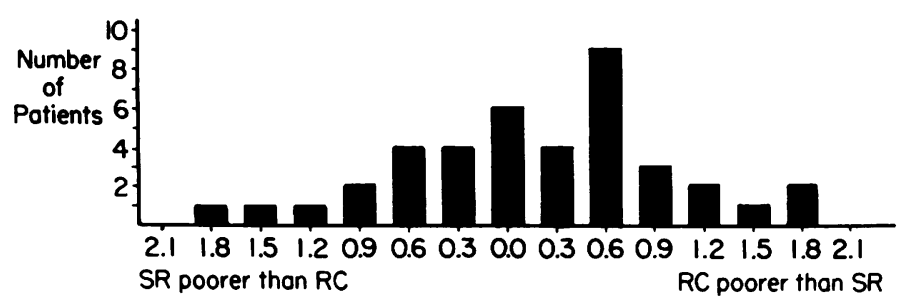

Figure Distributions of differences in comparisons of sound recognition (SR) with aural comprehension $(A C)$ and reading comprehension $(R C)$ 


\section{Discussion}

The results of the study are consistent with the hypothesis that some aural comprehension defects involve determinants which also affect sound recognition. In accord with previously reported findings which suggested this theory, all of the aphasics who failed in sound recognition were also impaired in aural comprehension. In addition, individual defects in sound recognition were consistently associated with aural comprehension defects of at least comparable severity. Although some aphasics with impaired aural comprehension showed significantly better, intact sound recognition, these aphasics' scores in aural comprehension were identical in range of severity to those of aphasics for whom sound recognition was impaired. Thus, impaired sound recognition appears to be symptomatic of a distinct type of aural comprehension disorder which, though more general in nature, is not necessarily of greater severity than other, more specifically linguistic types.

For aphasics as a group, the relationship between sound recognition and aural comprehension appeared to be unilaterally dependent in nature-that is, a relationship in which aural comprehension was always at least as impaired as sound recognition but in which sound recognition was sometimes better than aural comprehension. In contrast, the relationship between sound recognition and reading comprehension appeared to be non-dependent. In this instance, scores in sound recognition ranged from being significantly better to being significantly poorer than those in reading comprehension. In addition, some of the aphasics for whom sound recognition and aural comprehension were comparably impaired shnwed intact and/or significantly better reading comprehension. These findings suggest that the determinants of impaired sound recognition, while also affecting aural comprehension, do not necessarily affect reading comprehension.

Two alternative explanations for the occasional absence of sound recognition defects among comprehensive defective aphasics may be considered. One is that the relationship between sound recognition and aural comprehension is hierarchical in nature, and that sound recognition defects are characteristic only of a more severe, not qualitatively different, type of aural comprehension disturbance. This was clearly not the case since defects in sound recognition were observed in association with aural comprehension defects at all levels of severity. The other possibility is that sound recognition defects are independent aphasic symptoms with no direct relevance for aural comprehension. For this view to be supported, it would have been necessary to find additional aphasics for whom sound recognition was significantly poorer than aural comprehension. Thus, while it is true that some aural comprehension defects involved determinants which were independent of sound recognition, it is also true that no sound recognition defects involved determinants which were independent of aural comprehension.

In some respects, the present findings on sound recognition are similar to those obtained from studies of pantomime recognition. Like impaired sound recognition, impaired pantomime recognition is an uniquely aphasic symptom, ${ }^{13-15}$ and defects in pantomime recognition are associated consistently with comparably severe defects in reading comprehension, its linguistic counterpart. ${ }^{15}$ In addition, some aphasics for whom both reading comprehension and aural comprehension were severely impaired performed well in pantomime recognition. Thus, findings in both areas indicate that there are types of language comprehension defects in which related nonverbal abilities are also affected.

The findings on sound recognition and pantomime recognition also argue against viewing individual non-verbal symptoms as part of a single, unitary cognitive disturbance, as has been implied in the writings of Jackson, ${ }^{1}$ Head, ${ }^{16}$ and Goldstein, ${ }^{17}$ and in the conclusions of previous studies on sound recognition. As was noted above, some aphasics with impaired sound recognition performed normally in reading comprehension. Similarly, some aphasics with impaired pantomime recognition performed normally in aural comprehension. In both instances, therefore, it appeared that the "loss of the abstract attitude" of some aphasics occurred in a single sensory modality and, in at least some cases, these were analogous to other, more specifically linguistic impairments such as pure alexia.

The relevance of the findings to the clinical entity of pure auditory agnosia may be considered. As was noted above, no aphasic in the present study failed in sound recognition while passing aural comprehension, which is the performance pattern typically associated with auditory agnosia. At the same time, about 10 individual case studies have been reported of patients for whom the recognition of non-verbal sounds was impaired while aural language comprehension was intact. ${ }^{18}$ However, all these latter 
cases had documented or suspected bilateral lesions. Hence, they do not necessarily contradict the conclusion that some aural comprehension defects in aphasia involve determinants which also affect sound recognition. Instead, they suggest that some aspects of sound recognition are mediated by bilaterally represented structures which do not mediate aural language comprehension and that other aspects of sound recognition are mediated by lateralised neural structures which also mediate aural language comprehension.

This investigation was supported by research funds from the Veterans Administration and by Research Grant NS-00616 from the National Institute of Neurological and Communicative Disorders and Stroke. I would like to thank Dr AL Benton for his advice and encouragement during the course of the study.

\section{References}

1 Jackson $\mathrm{H}$. On afflictions of speech from disease of the brain. Brain 1878; 1:304-30.

2 Weinsenburg T, McBride K. Aphasia: A Clinical and Psychological Study. New York: Commonwealth Fund, 1935.

3 Zangwill A. Intelligence in aphasia. In: De Reuck A, O'Conner M, eds. Disorders of Language. Edited by A De Reuck and M O'Conner. Boston: Little Brown and Company, 1964.

4 Zangwill $O$. Intellectual status in aphasia. In: Vinken P, Bruyn G, eds. Handbook of Clinical Neurology, vol IV. Amsterdam: North Holland Publishing Company, 1969.

5 Alajouanine T, Lhermitte F. Non-verbal communication in aphasia. In: De Reuck A, O'Conner M, eds. Disorders of Language. Boston: Little Brown and Company, 1964.
6 Weinstein S. Defects concomitant with aphasia or locus of lesion in either hemisphere. Cortex 1964; 1:154-67.

7 Spinnler H, Vignolo L. Impaired recognition of meaningful sounds in aphasia. Cortex 1966; 2:337-48.

8 Faglioni P, Spinnler H, Vignolo L. Contrasting behaviour of right and left hemisphere-damaged patients on a discriminative and semantic task of auditory recognition. Cortex 1969; 5:366-89.

9 Vignolo L. Auditory agnosia: a review and report of recent evidence. In: Benton $\mathrm{AL}$, ed. Contributions to Clinical Neuropsychology. Chicago: Aldine, 1969.

10 Spreen O, Benton AL. Test of Sound Recognition. Iowa City: Department of Neurology, University of Iowa Hospitals, 1974.

11 Benton AL. Development of a multilingual aphasia battery: progress and problems. J Neurol Sci 1969; 9:39-48.

12 Benton AL, Hamsher K. Multilingual A phasia Examination. Iowa City: Department of Neurology, University of Iowa Hospitals, 1978.

13 Duffy R, Duffy J, Pearson K. Pantomime recognition in aphasic patients. J Speech Hear Res 1975; 18:115-32.

14 Gainotti G, Lemmo M. Comprehension of symbolic gestures in aphasia. Brain and Language 1976; 3:451-60.

15 Varney NR. Linguistic correlates of pantomime recognition in aphasic patients. J Neurol Neurosurg Psychiatry 1978; 41:564-8.

16 Head H. Aphasia and Kindred Disorders of Speech. London: Cambridge University Press, 1926.

17 Goldstein K. Language and Language Disturbances. New York: Grune and Stratton, 1948.

18 Ulrich G. Interhemispheric functional relationships in auditory agnosia. An analysis of preconditions and a functional model. Brain and Language 1968; 5:286-300. 